\title{
EXPERIÊNCIAS DIDÁTICAS EM ARQUITETURA E URBANISMO: O ENSINO DE DESENHO UNIVERSAL
}

\author{
EXPERIENCIAS DIDÁCTICAS EN ARQUITECTURA Y URBANISMO: LA ENSEÑANZA DE DISEÑO \\ UNIVERSAL
}

\section{EDUCATIONAL EXPERIENCES IN ARCHITECTURE AND URBAN PLAN DESIGN: UNIVERSAL DESIGN TEACHING}

\section{DORNELES, VANESSA GOULART}

Doutora, Universidade Federal de Santa Maria, e-mail: arq.vanessadorneles@gmail.coml

\author{
BINS ELY, VERA HELENA MORO \\ Doutora, Universidade Federal de Santa Catarina, e-mail: vera.binsely@gmail.com
}

\section{RESUMO}

O desenho universal é uma filosofia de projeto a ser considerada na concepcão de todos os espaços. Projetar considerando a diversidade humana não é uma tarefa fácil, é necessário o desenvolvimento dessa competência nos cursos de graduação em Arquitetura e Urbanismo. Este artigo apresenta a realização de seis experiências didáticas na disciplina de Urbanismo e Paisagismo II, da Universidade Federal de Santa Catarina. Para a realização destas experiências foram aplicadas doze estratégias de ensino de desenho universal que foram incorporadas durante todo o processo de projeto dos alunos. 0 objetivo desta disciplina era a criação de um projeto de um espaço aberto inclusivo, que foi sendo delineado ao longo do semestre pelos alunos. Cada etapa do projeto foi avaliada de acordo com critérios de desenho universal previamente definidos a fim de averiguar se os alunos incorporaram a filosofia do desenho universal em seus processos de projeto. Os resultados obtidos com a pesquisa permitiram elaborar recomendações para ensinar desenho universal em projetos. Neste artigo, são apresentadas as estratégias de ensino utilizadas, a avaliação dos trabalhos desenvolvidos pelos alunos e, para finalizar, recomendações de ensino de desenho universal.

PALAVRAS-CHAVE: Arquitetura e Urbanismo, Ensino, Projeto, Desenho Universal

\section{RESUMEN}

El diseño universal es una filosofía de diseño a ser considerada en la concepción de todos los espacios. Proyectar considerando la diversidad humana no es una tarea fácil, es necesario el desarrollo de esa competencia en los cursos de graduación en Arquitectura y Urbanismo. Este artículo presenta la realización de seis experiencias didácticas en la disciplina de Urbanismo y Paisajismo II, de la Universidad Federal de Santa Catarina. Para la realización de estas experiencias se desarrollaron doce estrategias de enseñanza de diseño universal que fueron incorporadas durante todo el proceso de proyecto de los alumnos. El objetivo de esta disciplina era la creación de un proyecto de un espacio abierto inclusivo, que fue siendo delineado a lo largo del semestre por los alumnos. Cada etapa del proyecto fue evaluada de acuerdo con criterios de diseño universal previamente definidos a fin de averiguar si los alumnos incorporaron la filosofía del diseño universal en sus procesos de proyecto. Los resultados obtenidos con la investigación permitieron elaborar recomendaciones para enseñar diseño universal en proyectos. En este artículo se presentan las estrategias de enseñanza utilizadas, la evaluación de los trabajos desarrollados por los alumnos y, para finalizar, recomendaciones de enseñanza de diseño universal. PALABRAS CLAVES: Arquitectura y Urbanismo, Enseñanza, Diseño, Diseño Universal

\section{ABSTRACT}

Universal design is a design philosophy to be considered in the design of all spaces. . Designing considering human diversity is not an easy task, the development of this competence in undergraduate programs in Architecture and Urbanism is required. This paper presents the realization of six student experiments in the discipline of Urbanism and Landscape II, of the Federal University of Santa Catarina. To carry out these experiments we developed twelve universal design teaching strategies that have been incorporated throughout the students' design process. The purpose of this course was to create an inclusive open space design, which was being outlined during the semester by the students. Each step of the project was evaluated, according to universal design criteria previously defined, in order to determine whether students have incorporated the universal design philosophy in their design processes. The results obtained with the research allowed to elaborate recommendations to teach universal design in projects. This paper presents the teaching strategies used, the evaluation of the projects developed by the students and, finally, universal design educational recommendations.

KEYWORDS::: Architecture and Urban Planning, Education, Design, Universal Design 


\section{INTRODUÇÃO}

O desenho universal (DU) é uma filosofia de projeto que visa conceber produtos, edificações e espaços abertos para o maior espectro possível de usuários (MACE et al., 1996), considerando-se suas diferenças, necessidades espaciais e limitações no uso do espaço. Portanto, espaços concebidos de acordo com esta filosofia permitem a inclusão e a não segregação, e possibilitam criar uma sociedade mais justa.

Para que o desenho universal seja difundido e os espaços se tornem de fato acessíveis, é preciso profissionais conscientes e capacitados a projetar espaços universais e, também, para avaliar os espaços não eficientes. As avaliações pós-ocupação de acessibilidade, por exemplo, proporcionam aos profissionais ampliar seu conhecimento sobre novas soluções de projeto, estimulando sua criatividade na elaboração de respostas que vão além das indicadas pelas normas técnicas de acessibilidade. Quanto maior a quantidade desses profissionais, maior a troca de experiências entre eles, mais avaliações de casos positivos e negativos serão verificadas e, assim, o conhecimento sobre como projetar espaços inclusivos aumentará. Quando a sociedade vivenciar, em sua rotina, os benefícios de espaços inclusivos poderá compreender sua importância e se tornará ativa na reivindicação desses espaços e, assim, exigirá profissionais mais capacitados. Essa relação entre profissionais, espaços e sociedade deve se retroalimentar, de forma a contribuir para a transmissão de conhecimento e o desenvolvimento de competências na área. No entanto, ainda há falhas nessa retroalimentação e acredita-se que o ponto inicial desse processo seja através do ensino. Entretanto, o ensino de desenho universal ainda constitui um desafio a professores de diferentes áreas no Brasil, como: design, Arquitetura, urbanismo, paisagismo e tecnologia de informação, principalmente por se tratar de uma temática relativamente nova ${ }^{1}$.

Este artigo é parte de uma pesquisa de doutoramento sobre estratégias de ensino de desenho universal que procurou apontar formas de introduzir tal filosofia projetual na formação de profissionais da área de Arquitetura e urbanismo, colaborando para a conscientização da importância de projetar espaços universais para todos (DORNELES, 2014). Para isto, escolheu-se a disciplina de Urbanismo e Paisagismo II, do Curso de Arquitetura e Urbanismo da UFSC, que integra duas dessas escalas, urbanismo e paisagismo, e cujo objetivo é o desenvolvimento de um projeto de espaços abertos ${ }^{2}$. Sabe-se que todo projeto de Arquitetura, urbanismo ou paisagismo deve ser concebido de acordo com as necessidades dos seus usuários. No caso dos espaços abertos, essa necessidade é ainda mais relevante, pois seu acesso é livre e irrestrito, podendo ser usufruído por pessoas com as mais diversas características ${ }^{3 .}$

A pesquisa contou com o desenvolvimento de seis experiências didáticas onde foram inseridas diferentes estratégias de ensino de desenho universal. Neste artigo são elencadas as estratégias de ensino desenvolvidas e demonstrados os resultados obtidos com a avaliação dos projetos dos alunos.

Para a realização desta pesquisa partiu-se do pressuposto que incorporar o desenho universal em uma disciplina projetiva e trazer a prática do projeto ao aluno é mais adequado ao seu aprendizado que uma situação de ensino onde há apenas a transmissão de conhecimento. Este pressuposto baseia-se na bibliografia de Donald Schön (2000) que considera que para desenvolver um profissional reflexivo, a ação e prática devem ser incorporadas à sua formação.

\section{DESENHO UNIVERSAL}

Desenho universal e desenho inclusivo são termos usados frequentemente e indistintamente, nos Estados Unidos, para descrever uma abordagem de design que implica em equidade e justiça social através do projeto. (OSTROFF, 2001, p. 15) ${ }^{4}$.

O termo "desenho universal" foi utilizado, pela primeira vez, pelo arquiteto Ronald Mace, em 1985, nos Estados Unidos, e consiste numa filosofia de projeto que visa criar espaços que não segreguem nenhuma pessoa, independentemente de suas características físicas ou habilidades (MACE, 1985. 454).

Apesar de esse termo ter sido publicado, primeiramente, em 1985, sua origem remonta o período pós-guerras nos países europeus e nos Estados Unidos (OSTROFF, 2001) e é decorrente da industrialização do mercado de trabalho, em que acidentes ocorriam com os trabalhadores em função de distrações ou problemas com maquinários (HERSSENS, 2011).

Para contextualizar o surgimento do desenho universal com outras áreas de estudo, vale lembrar que, no final da década de 40, houve surgimento do termo "ergonomia", na Inglaterra, que vinha substituir os termos "fisiologia do trabalho" e "psicologia do trabalho", adotados anteriormente, e o conceito "fatores humanos" (human factors) adotado nos Estados Unidos (IIDA, 2005). Na Arquitetura, Le Corbusier vinha realizando 
estudos para uma melhor adequação da habitação às proporções humanas (CORBUSIER, 2006), com a publicação do primeiro Modulor (1,75m de altura), em 1950, e do Modulor 2 (1,83m de altura), em 1955.

Nesse período, também em função da discussão em prol dos direitos humanos ${ }^{5}$, a questão da deficiência deixa de ser tratada a partir de um modelo médico e passa a ser considerada do ponto de vista social (DEVLIEGER et al., 2003). Essa mudança de paradigma é influenciada pelo surgimento e desenvolvimento das ciências sociais, como Antropologia, Psicologia e Sociologia, que passam a inspirar a área de Arquitetura e Urbanismo (HERSSENS, 2011).

Na década de 60, inicia-se o questionamento, em Arquitetura e Urbanismo, com relação às consequências dos preceitos do modernismo e a críticas em relação à perda da escala humana nas cidades e à própria qualidade das ambiências. Alguns dos críticos que valem ser lembrados são: Jane Jacobs, Kevin Lynch, Christopher Alexander, Amos Rapoport, Steen Eiler Rasmussen, Christian Norberg-Schulz e Edward Twitchell Hall, entre outros.

Assim, somando-se as questões históricas de pós-guerra e a industrialização às questões sociais e de crescimento nas áreas de conhecimentos sociais enquanto ciência, surge, também, a preocupação em tornar os espaços adaptados às pessoas com deficiência, definido, na época, como "design para necessidades especiais" (DFSN - Design for Special Needs) (HERSSENS, 2011).

Como, nos Estados Unidos, havia uma preocupação muito grande na reintegração de antigos combatentes na sociedade, desenvolveu-se, na década de 50, o desenho livre de barreiras, ou barrier free design, cuja intenção era eliminar as barreiras físicas e atitudinais, adaptar o ambiente construído ao acesso das pessoas com deficiência e etc. (OSTROFF, 2001).

Assim, primeiramente, lidou-se com o conceito do "barrier free design", que, aos poucos, foi se tornando um conceito mais social e humano e foi chamado de "social design" e, por último, transformou-se no conceito, utilizado até hoje, de "desenho universal" (universal design) (CAMBIAGHI, 2007), que, além de estar direcionado para a concepção de projeto, procura estabelecer condições de igualdade entre as pessoas e não ser um desenho para necessidades especiais, mas, verdadeiramente, inclusivo.

A intenção do desenvolvimento desse termo foi suprimir a ideia de adaptação de espaços por causa das pessoas com deficiência e proporcionar um conceito mais amplo de projeto, que não segregue nenhuma parcela da população e que possa passar despercebido aos olhos dos usuários em geral (STEINFELD, MAISEL, 2012).

Como o desenho universal é considerado uma filosofia de projeto, deve-se entender as relações humanas com o ambiente físico, ou seja, as necessidades espaciais. Assim, para que haja tal entendimento, as áreas de conhecimento da ergonomia (análise da atividade/tarefa) e da Psicologia Ambiental (análise do comportamento humano) contribuem para a compreensão dos aspectos sensoriais, cognitivos e físicos que influenciam a interação entre o homem e o ambiente físico.

As necessidades relativas ao uso dos espaços variam conforme as características físicas dos usuários e de suas habilidades em função das características dos ambientes. Sabe-se que uma pessoa com deficiência visual precisa de outras informações sobre o espaço do que as pessoas com boa acuidade visual ou de informações que possam ser apreendidas por outros sistemas sensoriais, como o uso de informação tátil em pisos e mapas. Uma criança ou pessoa de baixa estatura em um píer não consegue enxergar a paisagem se houver um guarda-corpo alto e fechado em alvenaria. Congregar as necessidades de todas as pessoas para criar espaços inclusivos é o objetivo da filosofia do desenho universal. Para que essa filosofia de projeto possa ser efetiva, arquitetos devem tê-la em mente desde o início do projeto e, para colocá-la realmente em prática, é necessário um conhecimento aprofundado das necessidades das pessoas (HEYLIGHEN; BIANCHIN, 2010). Para Herssens (2011), essa prática pode se tornar real quando arquitetos ouvirem as necessidades e experiências dos usuários, ou seja, dos experts, pois, só assim, é possível desenvolver espaços mais responsivos para e esses usuários. Portanto, é importante compreender que o conhecimento sobre as necessidades dos usuários deve ser buscado constantemente, pois saber tudo o que as pessoas querem e desejam leva tempo, por isso, é essencial que se continue tentando (FROYEN, 2012).

Para que o desenho universal seja incorporado ao processo de projeto de arquitetos e urbanistas, uma alternativa é pensar estratégias de ensino que possam ser utilizadas nas disciplinas de projeto de arquitetura, urbanismo e paisagismo e que permitam o desenvolvimento de projetos centrados nos usuários. Neste artigo são apresentadas experiências didáticas que exploraram tal temática. 


\section{AS EXPERIÊNCIAS DIDÁTICAS}

A disciplina de Urbanismo e Paisagismo II é oferecida aos acadêmicos do quinto semestre do curso de Arquitetura e Urbanismo da UFSC, e sua ementa da disciplina indica que o estudante deve desenvolver uma proposta de intervenção urbana, a partir de um projeto paisagístico e de organização de espaços, considerando a relação homem e ambiente e os condicionantes ambientais, sociais, históricos e econômicos. O objetivo é o desenvolvimento de um projeto de parque urbano na cidade de Florianópolis ou cidades vizinhas, desenvolvido em equipes.

A metodologia de projeto adotada compreende três etapas distintas6: 1a etapa - Levantamento de dados e condicionantes de projeto; $2^{2}$ etapa - Partido Geral; 3aㅡ etapa - Projeto Final, ampliação e detalhamento (ver Figura 1).

Figura 1: Organização das etapas de projeto
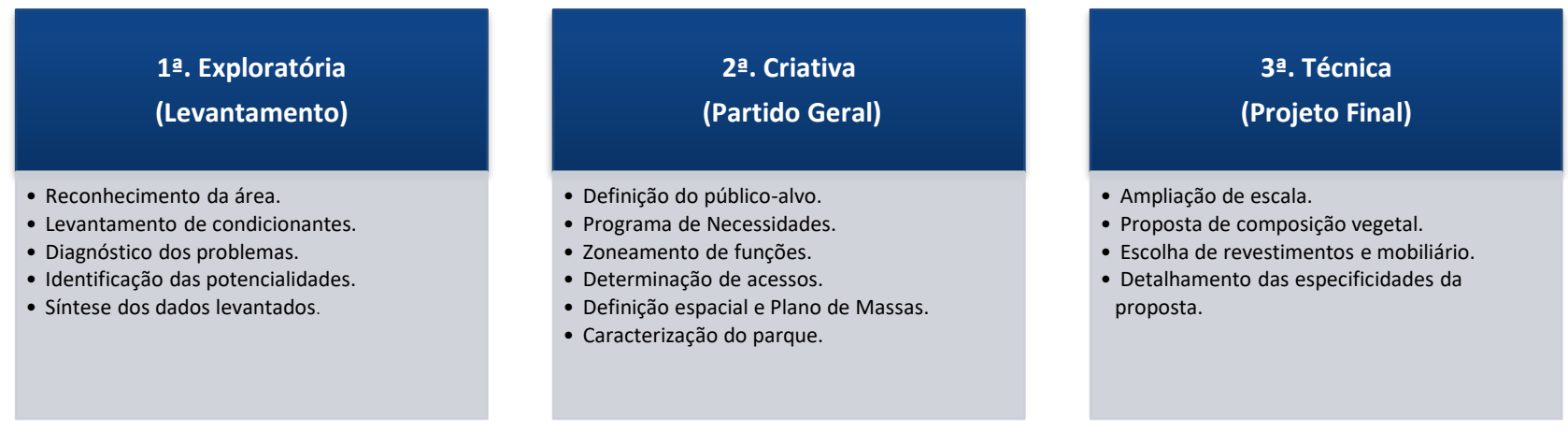

Fonte: Acervo dos autores

Na etapa exploratória, há a primeira aproximação com o tema e com a área de intervenção. Nessa fase, os acadêmicos devem avaliar a área do projeto e seu entorno, identificando os condicionantes físicos e humanos. Ao final desta etapa eles apresentam uma análise conclusiva do levantamento; um diagnóstico das potencialidades, carências e deficiências; e o programa de necessidades.

A segunda etapa da disciplina tem caráter propositivo, com a definição formal, o desenho do traçado e das circulações, a organização espacial do programa e a composição do plano de massas, que consiste na definição em terceira dimensão, com composições vegetais e de volumes de pequenas edificações.

Na terceira etapa, há um aumento do grau de definição da proposta, pela escolha dos elementos estéticos e funcionais que compõem os espaços do parque. Nesse momento, os acadêmicos fazem algumas correções da proposta apresentada na etapa anterior e definem uma parcela do parque a ser ampliada e detalhada. A área ampliada deve conter especificações e ilustrações dos revestimentos de piso, do mobiliário e da iluminação, bem como de todos os tipos de vegetação propostos.

Para o desenvolvimento da pesquisa, foram realizadas seis experiências didáticas que contaram com diferentes estratégias de ensino em forma de Infusão, ou seja, procurou-se inserir o desenho universal como tema de projeto (WELCH, 1995), que fosse recorrente durante todo o processo projetual.

Essas estratégias mudaram de acordo com cada experiência: algumas foram retiradas, outras aperfeiçoadas e, em novas experiências, adicionadas. Além disso, alterou-se a ordem de aplicação das estratégias.

Ao todo, foram aplicadas 12 estratégias diferentes de ensino7: 1) Aulas expositivas; 2) Leituras de artigos de DU; 3) Exercício de vivência; 4) Avaliação de acessibilidade; 5) Passeios acompanhados; 6) Pesquisa no blog; 7) Pesquisa no CD-ROM; 8) Seminários de exemplos de DU; 9) Fichas de dimensionamento; 10) Filmes de sensibilização; 11) Visita e observação de um grupo específico de usuários; e, 12) Assessoramentos de DU: 
1. As aulas expositivas consistiram no ministre de conteúdo referente à acessibilidade e ao desenho universal durante o semestre.

2. As Leituras de artigos corresponderam na disponibilização de dois artigos selecionados para que os alunos pudessem ler, elaborassem fichamentos e discutissem o assunto em aula. Normalmente, o tema do artigo estava relacionado com o tema a ser ministrado na aula expositiva.

3. Pesquisa no CD Desenho Universal aplicado ao paisagismo consistiu na disponibilização para os acadêmicos do CD multimídia com o título de Desenho Universal aplicado ao Paisagismo (BINS ELY et al., 2008), fruto de uma pesquisa finalizada em 2008 e desenvolvida pelo Grupo PetARQ/UFSC.

4. Pesquisa no blog desenho universal aplicado ao paisagismo foi desenvolvida a partir da segunda experiência, quando se sentiu a necessidade de disponibilizar, aos alunos, uma fonte de pesquisa na internet, voltada para o tema do desenho universal e do paisagismo com bibliografias gratuitas sobre o assunto, exemplos de espaços acessíveis e projetos pensados para estimular os sistemas sensoriais.

5. Os assessoramentos específicos quanto aos aspectos de desenho universal e acessibilidade ocorreram em diferentes momentos em cada experiência, com uma maior frequência na terceira etapa da disciplina. Durante os assessoramentos, os acadêmicos solicitaram ajuda para adequação dos pisos táteis, localização de mobiliário, iluminação e elementos de sinalização, bem como para configurar e detalhar as áreas de circulação do parque.

6. A avaliação de acessibilidade consistiu em uma avaliação de espaços abertos existentes a partir de aspectos e parâmetros de acessibilidade espacial. Na maior parte das experiências adotou-se o checklist de avaliação de acessibilidade, desenvolvido pela UFSC em parceria com o Ministério Público de Santa Catarina, para Edifícios Públicos (DISCHINGER et al., 2013), adaptado para espaços abertos

7. Os Seminários de exemplos de projetos universais foi um exercício prático de busca de referências de projetos que considerassem as necessidades espaciais de diferentes usuários.

8. As Fichas de dimensionamento também foi um exercício prático no qual os alunos deveriam desenvolver um pré-dimensionamento dos espaços que indicaram no Programa de Necessidades.

9. O exercício de vivência simulada consistiu em uma experiência para sensibilizar os alunos quanto às necessidades espaciais das pessoas com deficiência. Durante o exercício, eles deveriam realizar um percurso no campus da universidade, simulando dois tipos de deficiência: visual e de mobilidade.

10. Os filmes de sensibilização foram expostos durante as primeiras aulas expositivas sobre diversidade humana ou sobre desenho universal, exemplificando pessoas com deficiência superando situações que poderiam ser consideradas difíceis. A intenção dos vídeos não foi apenas sensibilizar o aluno quanto às diferenças entre as pessoas, mas mostrar que, mesmo se alguém possuir uma deficiência, isso não precisa impedi-lo de realizar quaisquer atividades.

11. O método do passeio acompanhado (DISCHINGER, 2000) foi utilizado a partir da segunda experiência didática como uma estratégia de ensino com o objetivo de aproximar o acadêmico da realidade das pessoas com deficiência.

12. A visita à $A C I C$ consistiu em visitas à Associação Catarinense para Integração do Cego com o objetivo de complementar a compreensão dos acadêmicos quanto às necessidades dos usuários. Esta estratégia ocorreu apenas na quarta e sexta experiências didáticas.

Para melhor compreender que estratégias estavam presentes em cada experiência didática, elaborou-se 0 Quadro 1, que indica se houve algum aprimoramento da estratégia de ensino em relação às aplicações anteriores. Por exemplo, as aulas expositivas foram melhoradas para a segunda experiência didática e sucessivamente para as demais experiências. A estratégia 2 - Leituras de artigos de DU - também foi melhorada, com a substituição dos artigos inicialmente utilizados por outros mais atuais.

Para entendimento dessas alterações, utilizaram-se os seguintes símbolos no Quadro1:

= Ausente nesta experiência

$=$ Presente nesta experiência

= Presente nesta experiência com aprimoramento em relação à aplicação anterior 
Quadro 1: Sistematização das estratégias de ensino em cada experiência didática

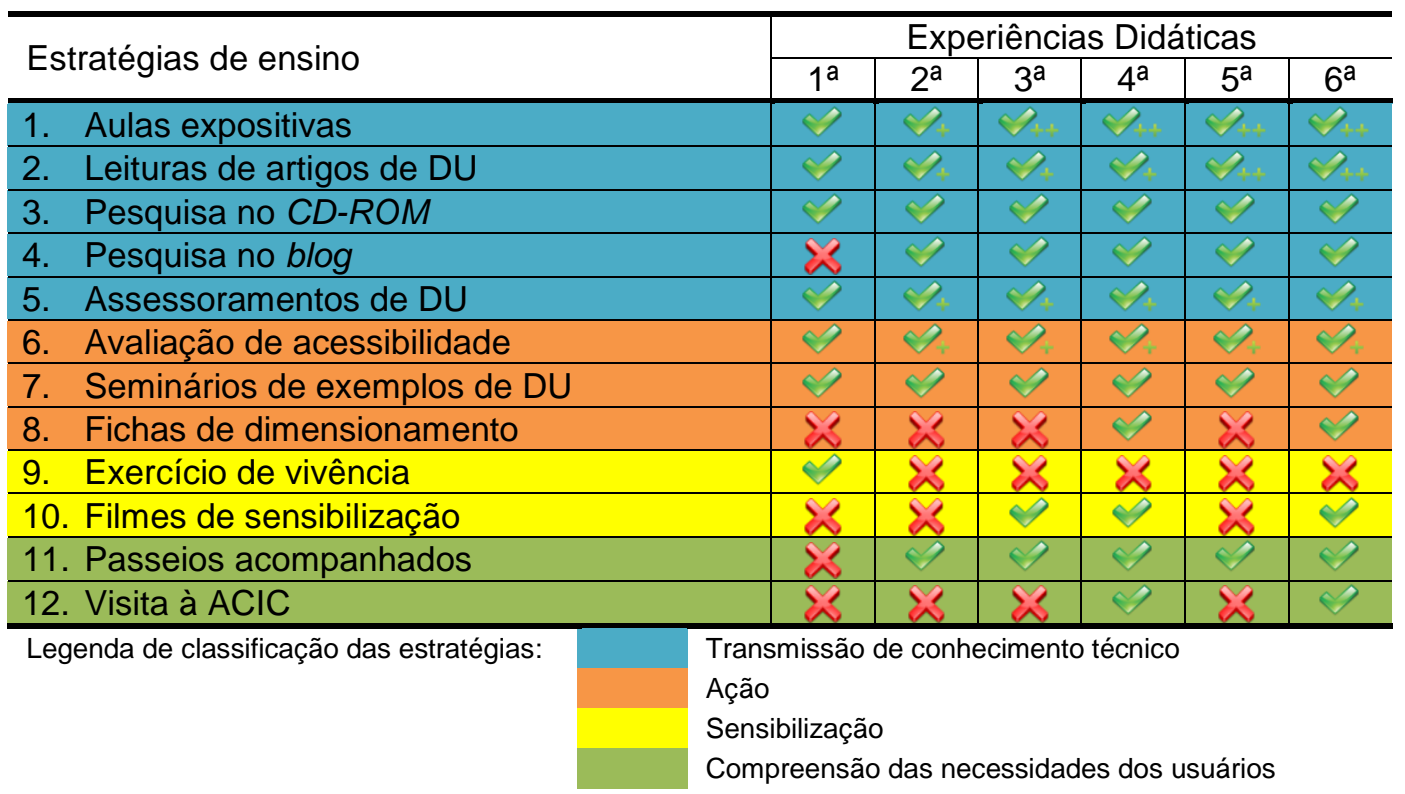

Fonte: Acervo dos autores

Vale ressaltar que as estratégias de ensino realizadas foram classificadas a partir de quatro funções principais (conforme Quadro 1): 1) transmissão de conhecimento, 2) ação (atividades práticas), 3) compreensão das necessidades dos usuários, e 4) sensibilização.

Tendo em vista a aplicação dessas doze estratégias ao longo de seis experiências didáticas, foi importante avaliar como tais estratégias contribuíram com o desenvolvimento de projetos inclusivos. Assim, foi elaborada uma metodologia de avaliação dos exercícios de projeto dos alunos a fim de analisar que experiências didáticas e estratégias contribuíram mais.

\section{METODOLOGIA DE AVALIAÇÃO DOS EXERCíCIOS DE PROJETO QUANTO À APLICAÇÃO DE DESENHO UNIVERSAL}

Para realizar essa avaliação, foram considerados três exercícios tomados como parte do processo projetual, que correspondem a diferentes etapas deste processo: 1) Programa de Necessidades, 2) Partido Geral e 3) Projeto Final.

No exercício do Programa de Necessidades, os acadêmicos deveriam determinar ambientes para o parque e refletir sobre os princípios de desenho universal a serem incorporados.

Para se avaliar esse exercício, foram analisadas três situações principais:

1. Havia espaços pensados especificamente para pessoas com deficiência, idosos ou crianças?

2. Os princípios do desenho universal foram indicados para esses espaços?

3. Havia ilustrações que demonstravam a inclusão dessas pessoas nos espaços?

O segundo exercício (Partido Geral), que consiste no primeiro lançamento da proposta do parque, os alunos realizavam a definição de ambientes, a previsão de dimensões aproximadas de espaços e circulações, os traçados formais e as massas vegetais. Para avaliar esse exercício quanto ao uso do desenho universal em projeto, foram considerados seis aspectos:

1. Existem espaços criados que consideram as necessidades de diferentes usuários?

2. Foram ilustrados (em croquis ou imagens) exemplos de espaços acessíveis como referência a ser utilizada no Projeto Final?

3. Houve alguma referência aos princípios de desenho universal?

4. Havia uma definição clara de hierarquia ${ }^{8}$ de caminhos que contribuísse para a orientação espacial? 
5. Havia uma setorização funcional de espaços, pensados conforme o público-alvo das atividades?

6. O uso da vegetação apresenta algum critério para colaborar para a orientação espacial?

Como esse exercício era entregue numa escala muito reduzida (normalmente, em 1:1000m), não foi possível avaliar mais especificamente se os trabalhos apresentavam características de desenho universal, mas já foi possível avaliar a lógica do projeto e suas intenções principais de acordo com as perguntas acima. Em geral, até essa etapa do projeto, os alunos já haviam tido aulas sobre desenho universal e acessibilidade e, dessa forma, já possuíam conhecimento sobre soluções de projetos inclusivos, como a questão da orientação espacial avaliada nas quatro últimas perguntas.

Para análise do Projeto Final, terceiro exercício projetual, que consiste numa ampliação de uma parte do parque na escala 1/200 ou 1/250, foi modificada a versão do checklist de avaliação de acessibilidade desenvolvido por Dischinger, Bins Ely e Piardi (2013). Optou-se por esse tipo de avaliação em função da padronização do instrumento e pela facilidade de sistematização dos critérios a serem avaliados. Acredita-se que uma avaliação do tipo análise de tarefa ou atividade da ergonomia seria mais adequada para a análise de desenho universal, entretanto, essa análise poderia se tornar subjetiva e recair em avaliações diferenciadas para cada equipe, tornando difícil a comparação entre os trabalhos.

O checklist de avaliação de acessibilidade original é voltado para análise de ambientes construídos fechados e, por isso, foi necessário realizar algumas modificações, como adequação dos critérios para espaços abertos e identificação de aspectos de projeto. Assim, para a avaliação dos projetos dos alunos, alguns critérios mais técnicos e de teor construtivo foram retirados. Por exemplo, os critérios de sinalização, como alturas de placas, formatos e cores, não foram avaliados. Critérios relacionados a detalhes construtivos ou de manutenção também foram descartados. Ao final, totalizaram-se quarenta e sete parâmetros de avaliação ${ }^{9}$.

Para os três exercícios, as respostas SIM indicavam que havia uma proposta considerando desenho universal e as respostas NÃO o oposto. Sendo que no checklist do terceiro exercício havia a possibilidade de responder "Não se aplica", quando o espaço a ser avaliado não existia na proposta dos alunos, ou ainda "Sem informação necessária", quando não era possível averiguar as condições de acessibilidade nos desenhos.

\section{RESULTADOS DAS EXPERIÊNCIAS}

Ao fim das seis experiências didáticas desenvolvidas nesta pesquisa, foram avaliados 28 projetos realizados por equipes de alunos. Ao todo, 101 estudantes participaram das experiências didáticas e foram organizados nessas 28 equipes, que tiveram diferentes configurações de acordo com a quantidade de acadêmicos na turma. A distribuição dos alunos nas experiências segue o Quadro 2:

Quadro 2: Organização dos alunos nas experiências didáticas

\begin{tabular}{l|c|c|c}
\hline & $\begin{array}{c}\text { Quantidade } \\
\text { de alunos }\end{array}$ & $\begin{array}{c}\text { Quantidade } \\
\text { de equipes }\end{array}$ & $\begin{array}{c}\text { Quantidade de } \\
\text { alunos por } \\
\text { equipe }\end{array}$ \\
\hline Primeira experiência didática & 26 & 8 & 3 e 4 \\
\hline Segunda experiência didática & 4 & 2 & 2 \\
\hline Terceira experiência didática & 15 & 4 & 3 e 4 \\
\hline Quarta experiência didática & 14 & 4 & 3 e 4 \\
\hline Quinta experiência didática & 29 & 7 & 4 e 5 \\
\hline Sexta experiência didática & 8 & 3 & 2 e 3 \\
\hline
\end{tabular}

Fonte: Acervo dos autores.

Conforme já explicado, a avaliação dos projetos dos alunos ocorreu em três etapas: 1) Programa de Necessidades; 2) Partido Geral; e 3) Projeto Final.

No primeiro exercício projetivo (Programa de Necessidades), os estudantes deveriam vincular os princípios do desenho universal ao programa, indicando como poderiam ser aplicados em cada espaço proposto. Esta avaliação foi realizada a partir de três aspectos relativos à proposição de espaços e a aplicação do conceito de desenho universal. Nesse primeiro exercício, de forma geral, a avaliação obteve um resultado insatisfatório, uma vez que o somatório das respostas em todas as experiências evidenciou 56\% de respostas "negativas" e 44\% de respostas "positivas". 
No primeiro critério referente à pergunta: 1) "Havia espaços pensados especificamente para pessoas com deficiência ou idosos?", houve uma grande porcentagem de respostas "positivas" nas seis experiências (82\%). As outras duas perguntas, 2) "Os princípios do desenho universal foram indicados nos ambientes pensados?" e 3) "Havia ilustrações que demonstravam a inclusão dessas pessoas nos espaços?", obtiveram poucas respostas "positivas", de forma geral, com $82 \%$ e $68 \%$ de respostas "não", respectivamente, conforme pode a Figura 2.

Figura 2: Gráfico geral da avaliação do Programa de Necessidades

Avaliação dos três critérios do Programa de Necessidades

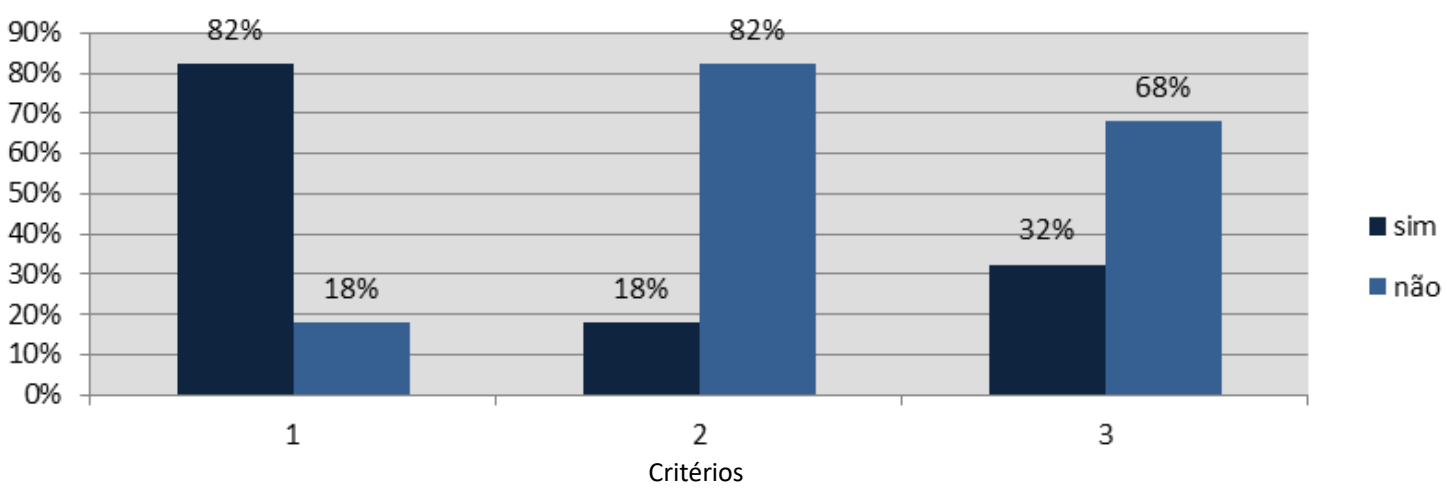

Fonte: Acervo dos autores

Esse resultado demonstra que, de forma geral, houve uma preocupação com a criação de espaços pensandose nos usuários, mas que não houve uma ênfase, por parte dos alunos, em indicar os princípios de desenho universal ou ilustrar soluções de inclusão nessa etapa.

Ao se comparar o resultado entre as experiências didáticas, ilustrado na Figura 3, percebe-se uma grande variação entre as porcentagens de respostas positivas e negativas ao longo das experiências. As duas primeiras experiências apresentaram porcentagens iguais entre respostas "sim" e "não", e, apenas na sexta experiência, houve predominância de respostas positivas, com um total de $89 \%$.

Figura 3: Gráfico por experiências didáticas da avaliação do Programa de Necessidades

\section{Avaliação do Programa de Necessidades em cada experiência}

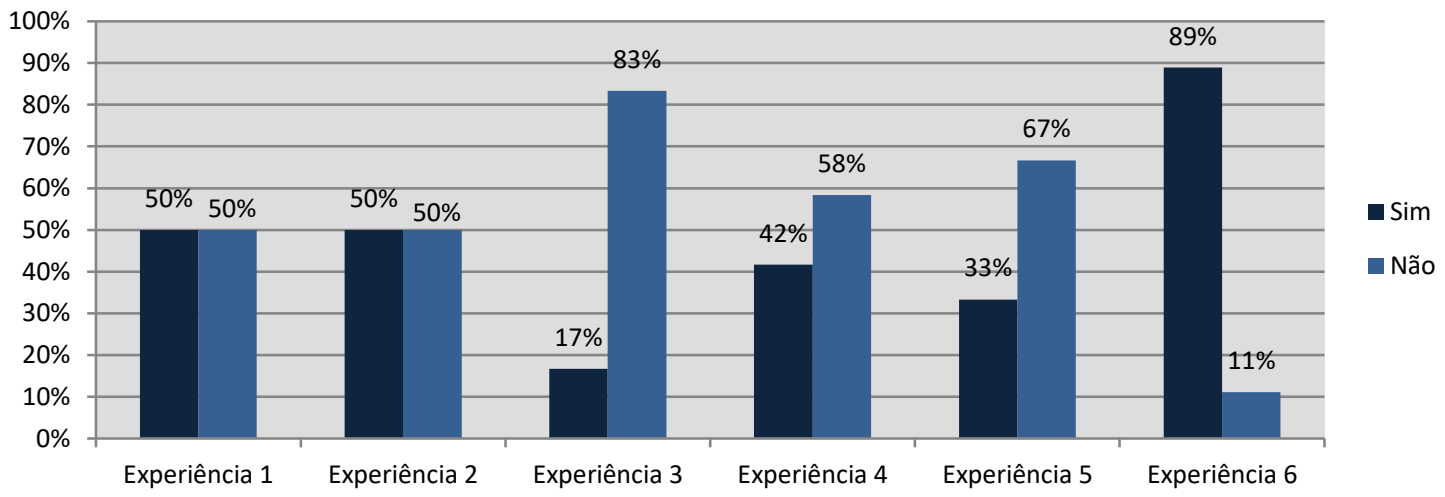

Fonte: Acervo dos autores

O segundo exercício avaliado consiste no Partido Geral do parque, com implantação e localização de todos os espaços, definição da massa vegetal e de circulações. Assim como no Programa de Necessidades, nesse exercício, os alunos também deveriam indicar como o desenho universal estava sendo abordado em seu projeto e ilustrar soluções de desenho universal. O exercício foi avaliado a partir de 6 critérios (Figura 4), e, 
em comparação com o primeiro exercício, teve uma melhora significativa em termos de aumento de respostas positivas, correspondendo a $61 \%$ do total de avaliações.

Figura 4: Gráfico geral da avaliação do Partido Geral

Avaliação dos seis critérios do Partido Geral

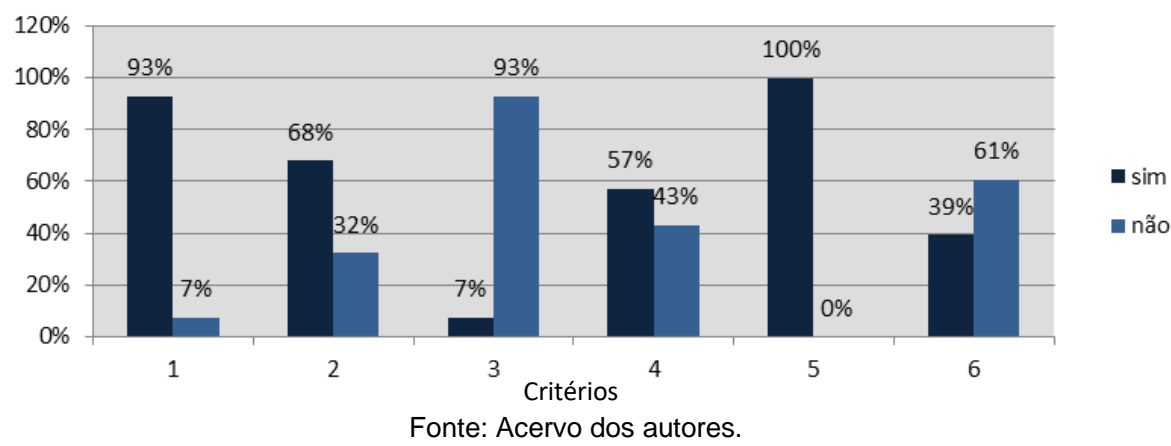

Em relação ao primeiro critério avaliado, "Os espaços criados consideram as necessidades dos usuários?", uma grande porcentagem dos trabalhos desenvolvidos (93\%) foi considerada positiva, principalmente por indicar espaços acessíveis ou públicos-alvo potenciais para os espaços. O segundo aspecto, "Foram ilustrados (em croquis ou imagens) exemplos de espaços acessíveis como referência a ser utilizada no Projeto Final?", também obteve uma resposta positiva, mesmo que não tão significativa quanto o primeiro, mas, ainda assim, satisfatória, uma vez que $68 \%$ dos trabalhos apresentaram exemplos de espaços acessíveis para ilustrar suas ideias. O terceiro critério, "Foram indicados os princípios de desenho universal?", foi o menos representativo, com apenas $7 \%$ de respostas positivas. Imagina-se que esse resultado negativo seja em função da dificuldade do aluno em caracterizar sua ideia como um princípio de desenho universal; em geral, havia apenas uma descrição da intenção de projeto em termos de condições de acessibilidade. $O$ quarto critério, "Havia uma definição clara de hierarquia de caminhos que contribuísse para a orientação espacial?", teve um resultado positivo, com $57 \%$ das respostas "sim" na avaliação geral das experiências didáticas. Esse resultado alerta que, ainda, uma boa porcentagem dos acadêmicos $(43 \%)$ não evidenciou a hierarquia de circulações no parque criado. O quinto critério, "Havia uma setorização funcional de espaços pensados conforme o público alvo das atividades?", foi o mais bem avaliado nessa etapa, com 100\% de respostas positivas, o que demonstra que os acadêmicos organizaram os espaços do parque considerando seus públicos e atividades. O sexto e último critério avaliado, "O uso da vegetação apresenta algum critério para contribuir com a orientação espacial?", foi o único aspecto com um resultado negativo, pois $61 \%$ dos grupos não consideraram a vegetação como critério para auxiliar o desenho universal do parque. Esse resultado é reflexo da pouca utilização de massas vegetais nessa etapa do projeto.

Ao se comparar os resultados obtidos com a avaliação do Partido Geral em cada uma das experiências, conforme ilustra a Erro! Fonte de referência não encontrada., pode-se perceber um resultado positivo, de forma geral, em que todas as experiências tiveram respostas "sim" majoritariamente, com variação entre $55 \%$ e $67 \%$.

Figura 5: Gráfico por experiências didáticas da avaliação do Partido Geral

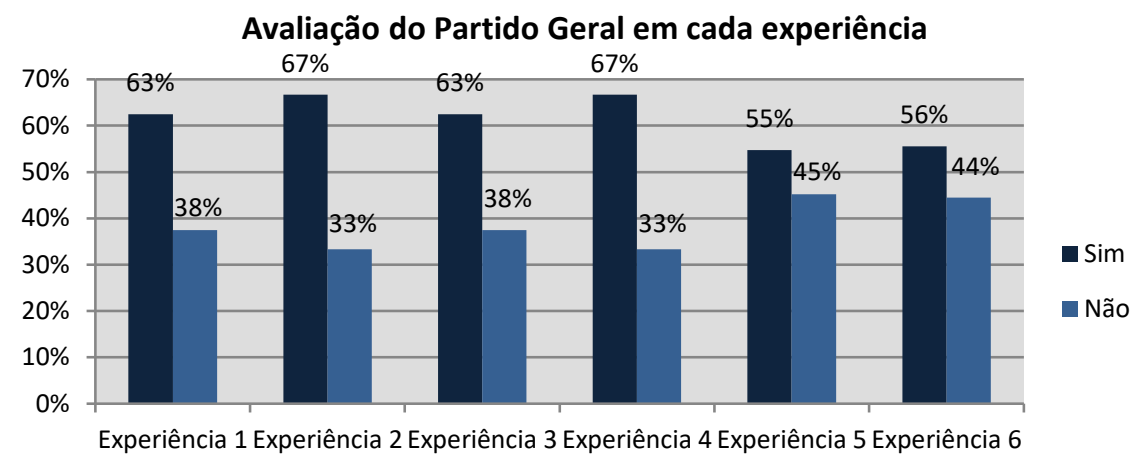

Fonte: Acervo dos autores. 
No terceiro exercício avaliado (Projeto Final), os acadêmicos fizeram a ampliação de uma área do parque onde deveriam especificar mobiliário, iluminação, revestimentos e vegetações de forma a colaborar para ou propiciar a acessibilidade a todas as pessoas, ou seja, a partir do desenho universal. A avaliação desse exercício foi realizada com um checklist de avaliação de projetos quanto a acessibilidade, com base nas planilhas desenvolvidas por Dischinger et al. (2013) para o Ministério Público de Santa Catarina. As respostas dessa avaliação não se restringiam apenas a "sim" e "não", incluíam também as respostas "NA/l", para quando a situação a ser avaliada não estivesse presente no projeto ${ }^{10}$, e "Sem informação necessária" para quando havia dúvidas na representação do projeto que pudesse aferir uma resposta positiva para o aspecto avaliado. Assim, de modo geral, obteve-se um resultado positivo nessa última etapa, uma vez que $66 \%$ dos projetos obtiveram respostas "sim", $11 \%$ respostas "não", $20 \%$ respostas "NA/l" e 3\% respostas "Sem informação necessária". Como foram 47 aspectos avaliados, preferiu-se apresentar seus resultados classificados a partir dos componentes de acessibilidade (orientação, deslocamento, uso e comunicação) ${ }^{11}$, conforme demonstra a Figura 6.

Figura 6: Gráfico geral da avaliação dos projetos finais

Avaliação dos projetos finais

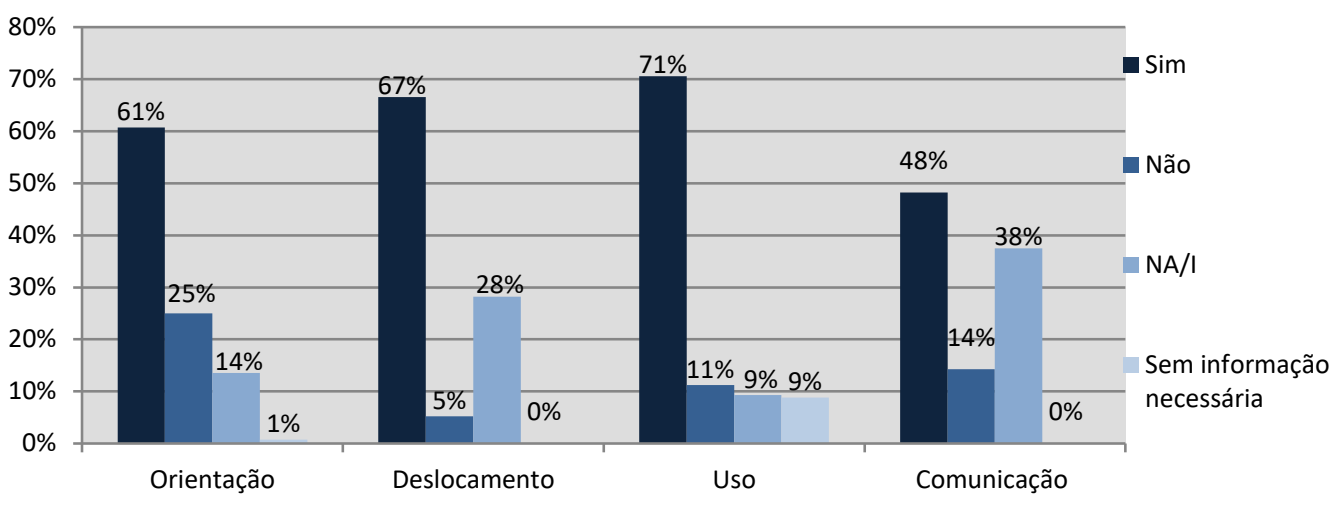

Fonte: Acervo dos autores.

O componente "orientação", que corresponde aos aspectos como presença de informações gráficas, táteis e visuais, que possibilitam saber onde se está no parque ou que caminhos seguir para chegar ao seu destino, obteve $61 \%$ de respostas positivas e $25 \%$ de respostas negativas. O componente "deslocamento", que corresponde a questões que facilitam a circulação das pessoas, como largura e altura livres, tipos de pisos, entre outros, obteve $67 \%$ de respostas positivas e apenas $5 \%$ negativas. O componente "uso", que representa aspectos como tipos de mobiliário e seus arranjos espaciais nos ambientes, foi o que obteve a maior porcentagem de respostas positivas entre os componentes, correspondendo a $71 \%$ do total. E, por último, o componente "comunicação", que corresponde a aspectos que facilitam a interação entre as pessoas, como presença de espaços para intérpretes ou configuração espacial de espaços que permita conversas frontais, obteve $48 \%$ de respostas positivas.

Em relação a essa avaliação, é importante salientar que a grande porcentagem de respostas positivas é representativa para o estudo. Entretanto, a pequena porcentagem de respostas "não" em cada um dos componentes é bem relevante também, já que, apenas no componente "orientação", essa porcentagem foi maior que $20 \%$; nos demais componentes, as respostas negativas foram menores que $15 \%$ do total. Ao se comparar os resultados obtidos em cada uma das experiências, pode-se verificar um resultado predominantemente positivo com todas as experiências, com maioria de respostas "sim" e com respostas "não" sendo bem pouco representativa, conforme a Figura 7. 
Figura 7: Gráfico por experiências didáticas da avaliação dos projetos finais.

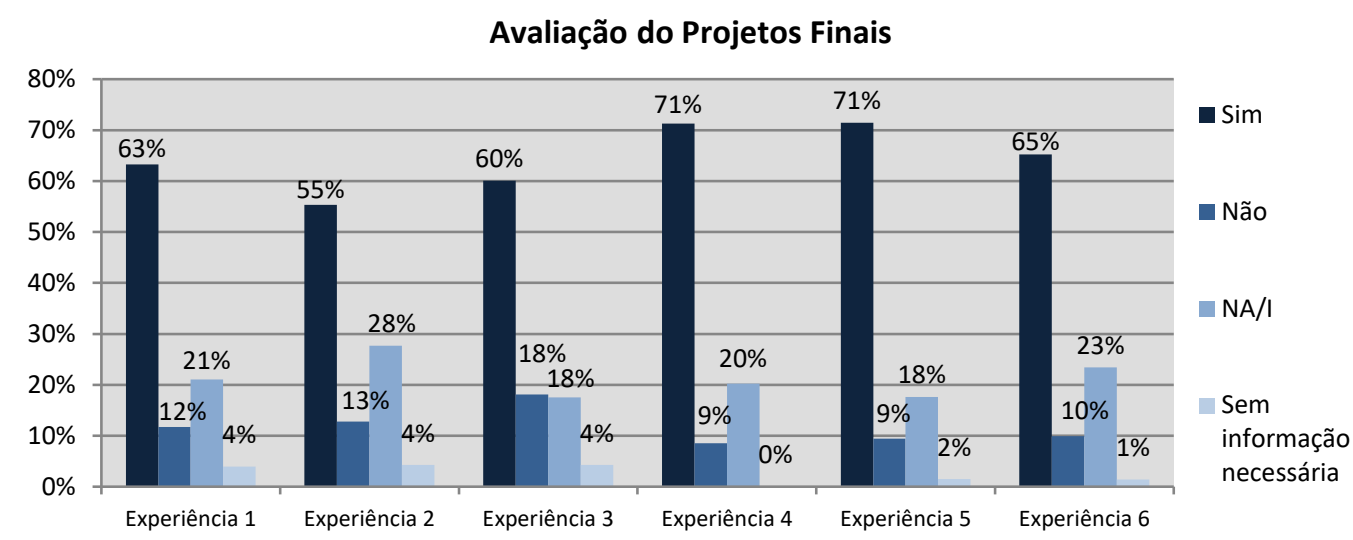

Fonte: Acervo dos autores.

Ainda em relação à Figura 7, vale ressaltar que, em todas as experiências, a porcentagem de respostas positivas foi acima de $50 \%$, com destaque para as experiências 4 e 5 , que obtiveram $71 \%$ de respostas positivas. Além disso, exceto pela experiência 3, que obteve $18 \%$ de respostas negativas, todas as experiências obtiveram menos de $15 \%$ de respostas negativas de forma geral. Essas porcentagens positivas foram reflexo de diversas soluções interessantes que os alunos desenvolveram ao longo das seis experiências didáticas.

Outra análise interessante quanto aos projetos dos acadêmicos é verificar sua evolução geral em todas as experiências ao se comparar os resultados positivos e negativos ao longo do semestre, nos três exercícios avaliados, conforme demonstra a Figura 8.

Figura 8: Gráfico da comparação geral entre os exercícios projetivos

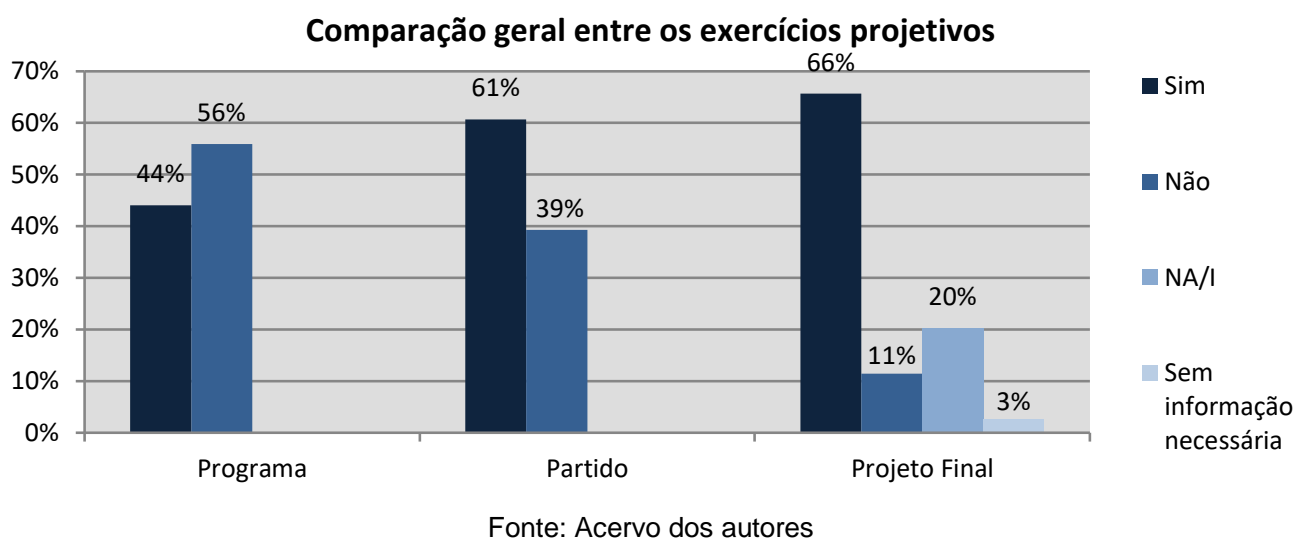

De forma geral, houve um aumento da porcentagem de respostas "sim": Programa obteve 44\%, Partido obteve $61 \%$ e Projeto Final obteve $66 \%$. Em relação às respostas "não", o declínio da porcentagem foi bastante representativo, iniciando em 56\% no Programa e chegando a apenas $11 \%$ no Projeto Final.

Ao verificar esse mesmo resultado em cada uma das experiências, é muito visível o aumento de respostas positivas e declínio de respostas negativas em todas as experiências, exceto na experiência 6. A sexta experiência se diferenciou das demais, pois os Programas de Necessidades já possuíam uma boa quantidade de respostas "sim" (89\%). Acredita-se que o resultado obtido em todas as experiências é reflexo das estratégias de ensino utilizadas desde o princípio do semestre, não apenas na terceira etapa, pois o conhecimento foi sendo sedimentado e, ao final do período, os alunos já possuíam conhecimento suficiente para aplicar o desenho universal em seus projetos.

Vale ressaltar ao fim das seis experiências que, ainda que os dados demonstrem resultados positivos em relação à aplicação do desenho universal nos projetos dos alunos, o fato da temática ter sido desenvolvida 
ao longo de uma disciplina projetiva foi muito interessante, pois trouxe uma real reflexão sobre as necessidades dos usuários e diversas discussões sobre como projetar espaços centrados nos usuários. Algumas das estratégias realizadas não só despertaram o interesse dos alunos pelo tema do desenho universal, como também contribuíram com diversas descobertas, como por exemplo, o passeio acompanhado, que ao ser realizado aproximou os alunos de possíveis usuários do seu projeto. Ouvir as pessoas e entender suas realidades foi uma experiência muito rica e trouxe muito aprendizado para todas as turmas.

Considerando todas as especificidades e aprendizados obtidos durante as seis experiências, a seguir são explanadas algumas recomendações de ensino que puderam ser desenvolvidas a partir do estudo realizado.

\section{RECOMENDAÇÕES PARA O ENSINO DE DESENHO UNIVERSAL}

Com base nas experiências didáticas foi possível identificar uma combinação de estratégias que geraram um bom resultado do ponto de vista do desenvolvimento do trabalho dos alunos. As recomendações a seguir estão baseadas em todas as experiências didáticas realizadas, e estão organizadas em três etapas, que representam as etapas do processo de projeto desenvolvidas: Exploratória, Criativa e Técnica (DORNELES et al., 2013).

\section{Etapa Exploratória}

As estratégias de ensino de desenho universal que podem ser inseridas correspondem a estratégias de transmissão de conhecimento, de compreensão das necessidades dos usuários, de ação e de sensibilização, não, necessariamente, nessa ordem.

As estratégias de transmissão de conhecimento devem incluir aulas expositivas e indicação de materiais de pesquisa e didáticos como: artigos, CD-ROM, blogs, sites e livros.

As aulas expositivas devem explorar questões conceituais sobre desenho universal, acessibilidade e diversidade humana, e exemplificar métodos para compreensão das necessidades dos usuários, como passeios acompanhados, entrevistas e walkthrough. Além disso, devem-se apresentar exemplos de conflitos espaciais e as barreiras de acessibilidade decorrentes de projetos que não consideraram as necessidades dos usuários.

As estratégias de compreensão das necessidades dos usuários é uma das mais importantes e, quando inseridas nessa etapa, prepara o aluno para lidar com esse entendimento ao longo do semestre. Neste trabalho foram utilizadas duas estratégias: Passeios acompanhados e Visita à ACIC, mas outras estratégias são, igualmente, interessantes, como realizar entrevistas individuais ou em grupos focais; fazer visitas em áreas residenciais ou de trabalho de pessoas com deficiência para entender sua rotina; organizar palestras ou mesas redondas com pessoas com deficiência para fomentar um debate sobre a relação do usuário com 0 ambiente.

As estratégias de sensibilização têm um grande potencial de fazer o acadêmico refletir sobre o papel da deficiência na sociedade e de como as pessoas com deficiência podem estar marginalizadas por barreiras arquitetônicas e/ou atitudinais. Assim, os exercícios de vivência permitem, ao acadêmico, colocar-se no lugar da pessoa com deficiência e entender a dificuldade em aprender a lidar com uma limitação. Os filmes de sensibilização podem contribuir para a reflexão sobre o modelo cultural da deficiência, pois, normalmente, as pessoas que possuem algum tipo de limitação são mostradas nesses filmes como exemplos de superação.

Como nessa etapa não há apenas o levantamento de condicionantes referentes às necessidades dos usuários, mas também inclui as informações de contexto urbano, legislações e normas, sugere-se que os dois tipos de levantamentos de condicionantes ocorram de forma distinta, tendo seu painel de apresentação separado.

\section{Etapa Criativa}

As estratégias de ensino que podem contribuir para essa etapa criativa do processo de projeto são aquelas que servem como estímulos à criação e busca de referenciais de projeto, como as de transmissão de conhecimento e as de ação.

Assim, as aulas expositivas devem expor exemplos de espaços acessíveis vinculadas aos conceitos trazidos na Etapa Exploratória. A leitura de artigos também deve envolver artigos e textos que exemplifiquem situações 
espaciais de inclusão, demonstrando que é possível projetar e construir espaços que considerem as necessidades dos usuários e que proporcionem condições de igualdade e justiça.

As estratégias de ensino classificadas como ação são as que contribuem para o estudante lançar suas ideias e desenvolver seu projeto. Assim, uma das estratégias que se aplica nessa etapa é o Seminário de exemplos de DU, em que os acadêmicos devem buscar referências de projeto que eles considerem interessantes e que, de alguma forma, tenham facilitadores aos usuários.

Outra estratégia interessante é o desenvolvimento de Fichas de dimensionamentos, nas quais os estudantes fazem uma previsão do espaço necessário para cada ambiente indicado no Programa de Necessidades. Essa estratégia colabora para que o aluno possa realizar uma composição formal e funcional da tipologia a ser criada de forma mais consciente, pois o volume de cada ambiente é definido de acordo com as atividades e a quantidade e os tipos de usuários.

\section{Etapa Técnica}

De forma geral, sugere-se o desenvolvimento de estratégias de transmissão de conhecimento técnico nesta etapa, como Aulas expositivas, Pesquisa em CD-ROM, Pesquisas em blogs ou redes sociais e Pesquisa em livros, apostilas e mesmo na NBR 9050.

As Aulas expositivas, nessa etapa, devem ser voltadas para exemplificar formas corretas de implementação dos aspectos técnicos de projeto, por exemplo, que tipos de materiais são mais adequados para circulações ou, ainda, como planejar a colocação de pisos e informações táteis no projeto. A Pesquisa em $C D$-ROM depende do tipo de multimídia utilizado, no caso do CD Desenho Universal aplicado ao paisagismo (BINS ELY et al., 2008), há um material didático sobre materiais e tipos de vegetação com informações de aplicação para estímulos dos sistemas sensoriais que pode ser explorado, nessa etapa, como transmissão de conhecimento técnico.

A pesquisa em blogs, redes sociais, livros, apostilas ou NBR 9050 serve, para o aluno, como um instrumento de consulta de informações técnicas ou exemplos que possam auxiliar suas tomadas de decisão nessa etapa do projeto.

Vale ressaltar, ainda, que os assessoramentos dos projetos em relação ao desenho universal, que consistem nas reflexões de professores e acadêmicos sobre como o projeto pode ficar mais adequado às atividades que se destina e às necessidades dos usuários, devem ocorrer ao longo de toda a disciplina. Essa estratégia consiste em um diferencial do ensino de Arquitetura e Urbanismo, pois é quando o professor (com papel de instrutor) troca experiências com o aluno. De acordo com Schön (2000), o diálogo entre aluno e professor ocorre graças a três características essenciais: "[...] acontece no contexto de uma tentativa de desenhar do estudante; faz uso de ações, bem como de palavras; e depende da reflexão-na-ação recíproca" (SCHÖN, 2000, p. 86). Assim, a partir dessa reflexão conjunta é possível melhorar e evoluir a proposta de projeto.

\section{CONCLUSÃO}

Projetar com o desenho universal não é um processo simples nem mesmo para profissionais e, assim, não se esperava que os alunos incluíssem o desenho universal em seus projetos tão facilmente. No entanto, as experiências didáticas foram satisfatórias, principalmente porque a avaliação dos Projetos Finais dos alunos foi muito positiva, com muitas soluções de desenho universal sendo incorporadas nas propostas dos parques.

Como as experiências didáticas foram realizadas numa disciplina efetiva do Curso de Arquitetura e Urbanismo, que não incorporava o desenho universal em sua ementa, foi um grande desafio incorporar estratégias de desenho universal numa disciplina que já compreendia uma grande complexidade de condicionantes e situações de projeto. Por outro lado, percebeu-se que ao logo do desenvolvimento das experiências, houve um aperfeiçoamento das estratégias e da abordagem do desenho universal com os alunos, permitindo uma evolução tanto dos alunos quanto dos pesquisadores.

Sabe-se que nem sempre é possível desenvolver disciplinas totalmente focadas no ensino do desenho universal, quando é possível, normalmente, são criadas disciplinas optativas na graduação ou na pósgraduação. Por isso, essas experiências foram tão pertinentes, pois permitem que outros pesquisadores e professores possam explorar as estratégias utilizadas, adaptando e evoluindo suas aplicações em qualquer tipo de disciplina, seja efetiva ou optativa. Sugere-se, principalmente, que ao se incorporar a temática do desenho universal nas disciplinas de projeto, que não seja apenas de forma normativa, com a cobrança da presença de parâmetros técnicos das normas de acessibilidade, por exemplo. Pois em geral os alunos acabam interpretando a acessibilidade como algo ruim e difícil de resolver, como um condicionante de projeto 
que prejudica o lançamento de propostas ousadas, criativas e elegantes. A intenção do desenho universal é o oposto disso, por se tratar de uma filosofia de projeto, sua intenção é auxiliar a todos no desenvolvimento da criatividade, criando espaços interessantes para todas as pessoas, promovendo a inclusão.

Ao final da pesquisa pode-se averiguar que projetar de forma universal não é apenas uma questão de conhecimento técnico, mas uma questão de atitude, de querer incluir as pessoas. O conhecimento adquirido pelos alunos durante as experiências é mais importante que a capacidade de avaliar critérios de acessibilidade. A capacidade de avaliação também é importante, principalmente no caso de técnicos de órgãos públicos ou de conselhos de fiscalização, que precisam aprender a avaliar ambientes construídos. Entretanto, as duas situações - aprender a projetar com desenho universal ou avaliar espaços quanto à acessibilidade - é facilitada se há o entendimento sobre as necessidades dos usuários e, principalmente, se houver empatia.

\section{REFERÊNCIAS}

BINS ELY, V. H. M.; DORNELES, V. G.; PAPALEO, M. K. Desenho Universal Aplicado ao Paisagismo: CD-ROM. Florianópolis: PetARQ/UFSC, 2008.

CAMBIAGHI, S. Desenho universal: métodos e técnicas para arquitetos e urbanistas. São Paulo: Editora Senac São Paulo, 2007.

LE CORBUSIER. Por uma arquitetura. São Paulo: Perspectiva 2006.

DEVLIEGER, P.; FRANK, R.; PFEIFFER, D. Rethinking Disability. Antwerpen - Apeldoorn: Garant, 2003.

DISCHINGER, M. Designing for all senses: accessible spaces for visually impaired citizens. Thesis (for the degree of Doctor of Phiolosophy) Göteborg, Sweden: Department of Space and Process School of Architecture, Chalmers University of Technology, 2000.

DISCHINGER, M.; BINS ELY, V. H. M.; PIARDI, S. M. D. G. Promovendo a acessibilidade nos edifícios públicos: Programa de Acessibilidade às Pessoas com Deficiência ou Mobilidade Reduzida nas Edificações de Uso Público. Florianópolis: Ministério Público de Santa Catarina, 2013.

DORNELES, V. G. Estratégias de ensino de desenho universal para Cursos de Arquitetura e Urbanismo. (Tese). Programa de Pós-Graduação em Arquitetura e Urbanismo (PósARQ), Universidade Federal de Santa Catarina, Florianópolis, 2014. 351p. p.

DORNELES, V. G.; AFONSO, S.; BINS ELY, V. H. M. O desenho universal em espaços abertos: uma reflexão sobre o processo de projeto. Gestão e Tecnologia de Projetos, v.v. 8, p.p. 55-67, jan.-jun. , 2013. http://dx.doi.org/10.4237/gtp.v8i1.251

FROYEN, H. Universal Design, a Methodological Approach. Boston: The Institute for Human Centered Design, 2012.

HERSSENS, J. Designing Architecture for More. A Framework of Haptic Design Parameters with the Experience of People Born Blind. (Doctoral thesis). Department of Arts and Architecture, PHL University College-University Hasselt: Association Faculty Universiteiten and Hogescholen Limburg, Hasselt, 2011.

HEYLIGHEN, A.; BIANCHIN, M. Can crap design be inclusive? In: Proceedings of the 5th Cambridge Workshop on Universal Access and Assistive Technology., March 22-25, p.55-62, 2010.

IIDA, I. Ergonomia: projeto e produção. São Paulo: Edgard Blücher, 2005.

MACE, R. Universal Design, Barrier Free Environments for Everyone. Los Angeles: Designers West, 1985.

MACE, R. L.; HARDIE, G. J.; PLACE, J. P. Accessible Environments: Toward Universal Design. Raleigh, NC: Center for Universal Design, 1996.

OSTROFF, E. Chapter 1. Universal Design: The new paradigm. In: Wolfgang F.E. Preiser e Elaine Ostroff (Ed.). Universal Design Handbook. New York: McGraw-Hill, 2001.

SCHÖN, D. A. Educando o profissional reflexivo: um novo design para o ensino e a aprendizagem. Porto Alegre: Artes Médicas Sul, 2000.

STEINFELD, E.; MAISEL, J. L. Universal Design Creating Inclusive Environments. Hoboken, New Jersey: John Wiley \& Sons, Inc., 2012.

WELCH, P. Strategies for Teaching Universal Design. Boston, USA: Adaptive Environments Center, 1995. 


\section{NOTAS}

1 Os estudos sobre a questão do desenho universal e o cuidado com as necessidades dos seres humanos no desenvolvimento de projetos teve maior repercussão a partir do final da década de 50 nos países europeus e nos Estados Unidos, com o desenho livre de barreiras (barrier-free design). O termo "desenho universal" começou a ser usado somente a partir de 1985, por Ronald Mace (OSTROFF, 2001). No Brasil, os estudos sobre o tema só começaram a ter uma maior repercussão a partir da década de 90.

${ }^{2}$ Neste artigo, os termos "espaços abertos" e "espaços livres" são utilizados como sinônimos e representam todos os espaços sem edificações que possam estar destinados ao lazer da população e que possuam livre acesso.

${ }^{3} \mathrm{O}$ projeto de espaços abertos deve considerar as necessidades de todas as pessoas, diferente do que ocorre em projetos de produtos e de algumas edificações que podem ser concebidos para grupos específicos ou para um único indivíduo.

${ }^{4}$ Tradução de: "Universal design and inclusive design are terms often used interchangeably in the United States to label a design approach that implies equity and social justice by design".

${ }^{5}$ A Declaração dos Direitos Humanos da ONU foi realizada em 1948.

${ }^{6}$ Maiores informações quanto ao desenvolvimento de um processo de projeto considerando o desenho universal está publicado no artigo: O desenho universal em espaços abertos: uma reflexão sobre o processo de projeto (DORNELES et al., 2013).

${ }^{7}$ A numeração utilizada nas estratégias de ensino corresponde apenas em sua identificação e não correspondem a ordem de aplicação das mesmas nas experiências didáticas, uma vez que em cada experiência houve alteração dessa ordem.

${ }^{8}$ Para avaliar se havia essa hierarquia, poderia ser através da diferenciação de dimensões dos caminhos, revestimentos ou uso de vegetação, que distinguissem os caminhos principais dos secundários.

${ }^{9}$ Este checklist adaptado encontra-se disponível para consulta na tese: DORNELES, Vanessa G. Estratégias de ensino de desenho universal para Cursos de Arquitetura e Urbanismo. (Tese). Programa de Pós-Graduação em Arquitetura e Urbanismo (PósARQ), Universidade Federal de Santa Catarina, Florianópolis, 2014. 351p. p.

${ }^{10}$ Por exemplo, não é possível avaliar se existem telas de proteção em quadras de esportes se o aluno não tiver projetado áreas esportivas no parque.

11 O checklist desenvolvido por DISCHINGER et al. (2013), originalmente, prevê a classificação de seus parâmetros técnicos de acordo com os componentes de acessibilidade: orientação, deslocamento, uso e comunicação.

NOTA DO EDITOR $\left(^{*}\right)$ O conteúdo do artigo e as imagens nele publicadas são de responsabilidade do(s) autor(es). 